\title{
Management of oligoprogression in patients with metastatic NSCLC harboring ALK rearrangements.
}

\author{
Chiara Pisano ${ }^{1}$, Marco De Filippis ${ }^{1 *}$, Francesca Jacobs ${ }^{1}$, Silvia Novello ${ }^{1}$, Maria Lucia Reale ${ }^{1}$ \\ 1 Department of Oncology, University of Turin, S. Luigi Gonzaga Hospital, Orbassano, Italy. Email: chiara.pi- \\ sano@unito.it; marco.defilippis@unito.it; francesca.jacobs2@gmail.com; silvia.novello@unito.it; realemarialu- \\ cia@gmail.com \\ * Correspondence: marco.defilippis@unito.it
}

Simple Summary: The growing efficacy and availability of new targeted systemic therapies have markedly improved the prognosis of metastatic lung cancer patients harboring ALK rearrangements. The use as long as possible of effective targeted therapies capable of maintaining a prolonged control of disease is paramount to ensure the best survival outcomes. In this regard, in case of oligoprogression, "beyond progression" systemic treatment added to local ablative therapies is considered a feasible option in the attempt of improving patients' life in quantity and quality, even if based on retrospective data. Certainly treatment of ALK rearranged lung cancer patients with oligoprogressive disease has to be individualized and based on multidisciplinary decisions, above all when further molecular targeted therapies are available - option that has to be always evaluated, especially in case of cerebral progression. In this review we provide an updated and comprehensive overview of the main treatment strategies in case of ALK rearranged oligoprogression.

\begin{abstract}
Personalized treatment based on driver molecular alterations, such as ALK rearrangement, has revolutionized the therapeutic management of advanced oncogene addicted NSCLC patients. Multiple effective ALK tyrosine kinase inhibitors (TKIs), with the amelioration of the activity at central nervous system level, are now available, leading to substantial prognosis improvement. The exposure to TKIs triggers resistance mechanisms and the sequential administration of other TKIs and chemotherapy is, for the most part, not targeted. In this context, extending the benefit deriving from precision medicine is paramount, above all when disease progression occurs in a limited number of sites. Retrospective data indicate that, in oligoprogressive disease, targeted therapy beyond progression combined with definitive local treatment of the progressing site(s) is an effective alternative. In these cases, multidisciplinary approach becomes essential for an integrated treatment strategy, depending on the site of disease progression, in order to improve not only survival, but also quality of life. In this review we provide an updated and comprehensive overview of the main treatment strategies in case of ALK rearranged oligoprogression, including systemic treatment as well as local therapy, and report real-world clinical stories, with the final aim of identifying the most promising management for this subset of patients.
\end{abstract}

Keywords: oligoprogression, NSCLC, ALK rearrangement.

\section{Introduction}

Over the last two decades the application of personalized therapies based on molecular features has radically changed the diagnostic and therapeutic approach in advanced non-small cell lung cancer (NSCLC). Specific oncogenic drivers have been identified and several targeted drugs are now available allowing a significant improvement in terms of response rate, survival and quality of life in molecularly selected patients.

Epidermal growth factor receptor (EGFR) mutations and anaplastic lymphoma kinase (ALK) rearrangements are the pillars of precision medicine in thoracic oncology, being the first molecular targets identified with substantial clinical implications. 
ALK rearrangements are detected in 3-7\% of advanced NSCLC and are typically associated with young age, non-smoking habit and adenocarcinoma histology[1]. Several types of ALK translocation have been discovered, all resulting from the fusion between ALK gene portion encoding for the intracellular tyrosine kinase domain (exons 20-29) and different partners, of which Echinoderm Microtubule-associated Protein like-4 (EML4) is involved in $90 \%$ of cases. This lead to the production of a chimeric protein with a constitutive tyrosine-kinase activity responsible for uncontrolled cellular proliferation[2]. Depending on the specific breaking point of the EML4 gene, more than 13 EML4-ALK fusion variants have been identified, with V1 (exons 1-13), V2 (exons 1-20) and V3 (exons 1-6) being the most common. A rapid bench to bedside approach from the detection of the ALK translocation in NSCLC permitted the development of several effective targeted therapy options.

Under drug pressure, however, the emergence of molecular resistance finally occurs with a median time to disease progression from 10.9 to 34.8 months[3][4]. Sequential administration of ALK TKIs up to chemotherapy represents a common therapeutic approach. In this context, extending the benefit deriving from targeted treatment is paramount, above all when disease progression occurs in a limited number of sites, defining the so-called oligoprogressive state. Oligoprogression is, indeed, relatively common in oncogene-addicted NSCLC, involving about $30-50 \%$ of patients in the course of targeted treatment, a higher percentage if compared to patients treated with immunotherapy or chemotherapy[5], raising the crucial question on the best treatment approach: change of systemic treatment or treatment prosecution beyond progression combined with local ablative therapy.

In this review we provide an updated and comprehensive overview of the main treatment strategies in case of ALK rearranged NSCLC oligoprogression, including systemic treatment as well as local therapy. We report two real-world clinical stories that prove the importance of multidisciplinary involvement and discussion in oncogene addicted patients with an oligoprogressive disease.

\section{Oligoprogression in oncogene-addicted disease: focus on ALK-rearranged NSCLC}

Traditionally, metastatic disease has been regarded as incurable, regardless of number of metastases, with local therapy restricted to palliation of symptoms. However, this paradigm has recently been questioned. In 1995 Hellman and Weichselbaum first introduced the concept of oligometastatic disease (OMD), an intermediate state between localized and widespread tumor in which metastases are limited in number and location; compared with more advanced stages, OMD is more indolent and it is more amenable to ablative therapy for metastatic lesions[6]. Patients may present with de novo OMD (synchronous OMD) or with limited relapse after treatment with curative purpose (metachronous OMD). Ablative local treatment (e.g. radiotherapy, radiofrequency, crioablation and surgery) to all metastatic sites with radical intent has shown to be potentially curative and associated with long-term survival benefit in several types of cancers, including NSCLC[7]. The precise definition of oligometastatic NSCLC is still a matter of debate in term of number of lesions and sites involved. Studies conducted in oligometastatic NSCLC often used different cut-offs for number of metastases (generally not exceeding five), diverse eligibility criteria and various stadiation methods creating challenges in interpretation of clinical trial results[7]. To standardize inclusion criteria for future clinical trials, The European Organisation for Research and Treatment of Cancer (EORTC) Lung Cancer Group proposed a maximum of five metastases and three organs involved, without diffuse serosal metastases or bone marrow involvement, as long as all lesions are amenable to treatment with radical intent[7].

The concept of OMD led to the recognition of other disease states in which local ablative therapies (LATs) may have a potentially curative role. Oligopersistent or oligoresidual disease definition refers to patients who present with oligometastatic disease after an 
excellent response to systemic therapy[8]. Likewise, the definition of oligoprogressive disease was first introduced in 2012 to describe widespread systemic tumor at diagnosis which shows, after a prolonged response or, at least, a stability of disease on systemic treatment, a limited progression in few metastatic sites and organs[9].

As mentioned above, oligoprogression is a common phenomenon in patients with oncogene-driven NSCLC treated with TKIs. Despite optimal initial response, progression eventually develops and, in roughly half of cases, relapse is limited to few sites[9]. This pattern of progression is essentially explained by:

Pharmacokinetic failure: differently from next generation TKIs, first-generation EGFR and ALK-TKIs have inadequate blood brain barrier (BBB) penetration, hence isolated central nervous system (CNS) progression is easily detected[10][11];

Intratumor and intertumor heterogeneity: resistant sites of disease may harbour a unique genomic profile, different from the primary tumor; drug pressure resulting from systemic targeted treatment prompt both the selection of intrinsically resistant cell clones and, after prolonged exposition, the development of acquired resistance mechanisms[12].

Differently from widespread systemic progression, oligoprogression may be managed by not only changing systemic therapy, but also maintaining the same systemic treatment beyond progression and adding metastasis-directed therapy to primary systemic treatment. Given the prognostic and therapeutic implications, an accurate pre-treatment staging is required to define oligoprogressive disease and select those patients who will most likely benefit from the addition of aggressive local treatments. Compared with computed tomography (CT) alone, positron emission tomography/ computed tomography (PET/CT) has greater sensitivity for staging mediastinal lymph nodes and detecting distant and occult metastases[13]. In the retrospective study by $N g$ TL and colleagues, PET/CT showed higher sensitivity in detecting oligoprogressive disease than CT $(81.3 \%$ vs $68.6 \%)$ in metastatic EGFR mutated, ALK+, or ROS1+ NSCLC patients on an active TKI[14]. In 15 advanced ALK+ NSCLC patients, PET/CT was able to detect progressive disease earlier than CT in nearly half of the assessments[15]. Brain magnetic resonance imaging (MRI) has a greater ability to identify intracranial metastases compared with CT and, together with PET/CT, ensure an accurate detection of oligoprogressive disease[16].

\section{Local ablative therapies in oligoprogressive ALK-rearranged NSCLC}

LATs to all progressing lesions in oligoprogressive, molecularly driven NSCLC is thought to potentially eradicate the TKI-resistant subclones, prevent secondary seeding and restore overall sensitivity of metastatic sites to the ongoing systemic treatment, until new resistant subclones emerge. Metastases-directed therapy approach enable to extend the duration of targeted therapy and delay the switch to the next systemic treatment as long as possible, thus prolonging TKIs benefit and improving survival.

Stereotactic radiotherapy (SRT), an advanced radiotherapy technique with high local tumor control rates and low toxicity, is the most frequently adopted method in case of oligoprogressive, oncogene-driven NSCLC[17]. SRT includes stereotactic body radiation therapy (SBRT), which delivers high doses in few courses, and stereotactic radiosurgery (SRS), which delivers a single ablative dose and is especially used for brain lesions. The addition of ALK-TKIs to radiotherapy can increase radiosensitivity of tumor cells strengthening the rational for compound strategies. Indeed, in preclinical studies it has been shown that crizotinib elicits beneficial effects in combination with radiotherapy in ALK-positive NSCLC cell lines by reducing tumor proliferation, microvascular density and perfusion[18][19]. In another study the antiproliferative effect of TAE684, a potent second generation ALK inhibitor that overcomes crizotinib resistance, was augmented by radiotherapy in EML4-ALK positive lung cancer cells[20]. On the other hand, another recent preclinical study reported that treatment with ALK-inhibitors combined with 10 Gy- 
irradiation led to similar effects to those of sole radiotherapy, with no clear evidence of sensitization to radiation by treating EML4-ALK mutated cells with ALK inhibitors[21].

Despite these preclinical heterogeneous data, as a matter of fact, local therapies (including radiotherapy or surgery approaches) combined with targeted therapy prosecution is a current common habit. Clinical evidences, indeed, even if mostly retrospective, support metastases-directed therapy approach (Table 1). Weickhardt and colleagues conducted a retrospective observational study to evaluate the benefits of LAT (radiotherapy or surgery) to oligoprogressive sites and continuation of crizotinib or erlotinib in patients with metastatic ALK-rearranged $(n=15)$ or EGFR-mutant $(n=10)$ NSCLC, respectively. PFS1 was 9 months for patients treated with crizotinib and 13 months for patients treated with erlotinib. Patients with good ECOG PS $(\leq 2)$ and non-leptomeningeal encephalic progression and/or $\leq 4$ extra-CNS sites of progression were deemed suitable to receive LATs. Twenty-five of 51 patients (49\%) who progressed were judged suitable for local therapy (15 ALK+, 10 EGFR-MT), twenty-four patients received radiotherapy while one patient underwent surgery. Post-LAT, 19 of 25 patients progressed again, with median PFS from the time of first progression (PFS2) of 6.2 months. In patients with isolated CNS progression, median PFS2 was of 7 months[9].

Two years later, the same group examined the safety and efficacy of LAT in ALKrearranged NSCLC patients with extra-CNS (eCNS) disease oligoprogression during crizotinib therapy. Of 38 patients analyzed, 33 experienced disease progression. Of these, 14 had eCNS progression suitable for radiotherapeutic LAT $(<4$ progressing lesions and ECOG performance status $0-1$ ). Of note, one patient received adrenalectomy followed by an additional course of radiotherapy. Median PFS1 and median eCNS PFS1 in the 38 ALK+ patients were 9.1 months (1.1-41.1 months) and 17 months (1.1-34 months), respectively. Median duration of crizotinib exposure was 28 months in the LAT cohort versus 10.1 months for non-locally treated patients. Median PFS1 for patients receiving LAT was 14 months versus 7.2 months for those receiving only systemic therapy. For patients undergoing LAT, median eCNS PFS2 was 5.5 months (1-27 months) and local control rates at 6 and 12 months were 100\% and 86\%, respectively. The two-year OS in patients receiving more than 12 months of crizotinib was $72 \%$ versus $12 \%$ in those receiving less than one year of therapy $(\mathrm{P}<0.0001)$. LAT proved to be safe with an excellent toxicity profile; the only grade 2 side effect was fatigue while no acute or delayed grade 3-5 side effects were observed[22].

Liu et al reported the data derived from 38 ALK- or ROS1-positive patients treated with crizotinib "beyond progression" for a median period of 5.9 months. They found that median PFS2 was numerically longer among patients who received local therapy compared to those who did not receive it, even if the difference was not significant (9.9 versus 4.2 months, $\mathrm{p}=0.094)[23]$.

In a recent multicenter retrospective study, Kroeze et al assessed the efficacy of SRT concurrent to immunotherapy or targeted therapy in 108 NSCLC patients $(60 \%$ on antiEGFR/ALK TKIs). Fifty-six percent of patients was treated for oligoprogressive disease (5 or less metastatic lesions) with brain being the most targeted site for SRT. Median PFS in oligoprogressive patients was 10.4 months. Second progression after LAT was once again oligoprogression in $59 \%$ of cases, regardless of the systemic treatment received $(\mathrm{p}=0.765)$. After 1 year, $58 \%$ of patients was still receiving the same systemic treatment as at the time of SRT. The median time to switch systemic treatment in oligoprogressive patients was 14 months (5.7-22.3 months). The following line was a new targeted therapy in $68 \%$ of cases[24].

In another recent multicenter retrospective study, Borghetti et al evaluated the outcomes of 106 NSCLC patients with EGFR mutations and ALK rearrangements treated with radiotherapy concomitant to TKI. Fifty-two patients (42\%) were defined as oligometastatic/oligoprogressive (up to 4 metastatic lesions). The most radio-treated sites were brain, bone and lung. Patterns analysis of disease recurrence after radiotherapy suggested that oligometastatic/oligoprogressive patients more frequently developed 
oligoprogression as subsequent tumor relapse. The 1- and 2-year OS rates in oligometastatic and oligoprogressive patients were $79 \%$ and $61.8 \%$, respectively[25].

$\mathrm{Ni}$ et al examined patterns of disease progression and the value of salvage radiotherapy in 93 ALK+ NSCLC patients treated with crizotinib. Progression rates at 12 and 24 months were $76.9 \%$ and $90.4 \%$, respectively, with a median PFS1 of 11.5 months (95\% CI; 9.8 - 13.2 months). Fifty percent of patients experienced disease progression at the original site, $23.1 \%$ developed metastases at sites not involved at the time of diagnosis and $26.9 \%$ of patients progressed in both sites. Brain was the most common site of disease progression, followed by lung and bone. Of the 52 patients with disease progression, 19 underwent salvage radiotherapy: 8 patients received whole brain radiotherapy (WBRT), 5 patients underwent brain SRS and 6 received extra-cranial SBRT. These patients achieved a higher PFS2 than those who did not receive salvage radiotherapy at crizotinib progression (10.0 versus 6.0 months). In addition, patients who received any radiotherapy treatment during the course of disease had a longer OS than those treated exclusively with TKIs $(\mathrm{p}=0.048)[26]$.

Table 1. Selected trials of oligoprogressive NSCLC patients treated with local ablative therapies combined with TKI.

\begin{tabular}{|c|c|c|c|c|c|c|c|}
\hline Author (year) & Type of study & N. of patients & $\begin{array}{l}\text { Molecular } \\
\text { status }\end{array}$ & LAT & Sites & $\begin{array}{c}\text { mPFS } \\
\text { (months) }\end{array}$ & mOS (months) \\
\hline $\begin{array}{l}\text { Weickhardt AJ } \\
\text { et al. (2012) }\end{array}$ & Retrospective & 25 & $\begin{array}{c}\text { EGFR+, ALK+ } \\
(54 \%)\end{array}$ & $\begin{array}{l}\text { SBRT, SRS, } \\
\text { WBRT, XRT, } \\
\text { surgery }\end{array}$ & $\mathrm{CNS}+\mathrm{eCNS}$ & $6.2 *$ & - \\
\hline $\begin{array}{c}\text { Gan GN et al. } \\
(2014)\end{array}$ & Retrospective & 14 & ALK+ $(100 \%)$ & $\begin{array}{l}\text { SBRT, HRT, } \\
\text { surgery }\end{array}$ & eCNS & $5.5^{*}$ & 39 \\
\hline $\begin{array}{c}\text { Liu J et al. } \\
\text { (2018) }\end{array}$ & Retrospective & 13 & $\begin{array}{c}\mathrm{ALK}+(86.8 \%) \\
\mathrm{ROS1+}\end{array}$ & SBRT, WBRT & $\mathrm{CNS}+\mathrm{eCNS}$ & $9.9 *$ & - \\
\hline $\begin{array}{c}\text { Kroeze SGC et } \\
\text { al. }(2021)^{\wedge}\end{array}$ & Retrospective & 108 & $\begin{array}{c}\text { EGFR+, ALK+ } \\
(15 \%), \text { ROS1+, } \\
\text { WT }\end{array}$ & SRS, SBRT & $\mathrm{CNS}+\mathrm{eCNS}$ & 8.7 & - \\
\hline $\begin{array}{l}\text { Borghetti P et al. } \\
\text { (2019) \$ }\end{array}$ & Retrospective & 106 & $\begin{array}{c}\text { EGFR+, ALK+ } \\
(19 \%)\end{array}$ & SRT, HRT & $\mathrm{CNS}+\mathrm{eCNS}$ & - & 23 \\
\hline $\begin{array}{c}\text { Ni J et al. } \\
\text { (2019) }\end{array}$ & Retrospective & 19 & ALK+ $(100 \%)$ & $\begin{array}{c}\text { SBRT, SRS, } \\
\text { WBRT }\end{array}$ & $\mathrm{CNS}+\mathrm{eCNS}$ & $10 *$ & - \\
\hline Takeda $\mathrm{M}$ et al & Retrospective & 7 & ALK+ (100\%) & WBRT, SRS & CNS & $5.5^{*}$ & - \\
\hline
\end{tabular}

LAT: local ablative therapy; mPFS: median progression-free survival; mOS: median overall survival; TKI: tyrosine kinase inhibitor; HRT: hypofractionated radiotherapy; SBRT: stereotactic body radiation therapy; SRS: stereotactic radiosurgery; XRT: standard radiation therapy; SRT: stereotactic radiotherapy; WT: wild-type; CNS: central nervous system; eCNS: extra-CNS.

* Calculated from progression on TKI.

$\wedge$ The study included both oligoprogressive ( $\leq 5$ metastatic sites) and polyprogressive ( $>5$ metastatic sites) patients. In oligoprogressive patients (56\%) mPFS was 10.4 months.

$\$$ The study included both oligoprogressive/oligometastatic $(\leq 4$ metastatic sites) and polyprogressive ( $>5$ metastatic sites $)$ patients. Fifty-two patients were defined as oligometastatic/oligoprogressive. SRT with an ablative intent was administered in 49 patients.

\section{The importance of managing CNS disease: local therapy and systemic treatment}

ALK+ NSCLC is characterized by a marked neurotropism due to an intrinsic high affinity for nervous tissue of ALK rearranged cancer cells. Brain metastases are reported in approximately $26-40 \%$ of ALK rearranged patient at diagnosis, in $46-63 \%$ after a previous line of treatment with ALK-TKI and up to $75 \%$ after two or more ALK TKIs [27][28].

Isolated CNS progression with controlled extracranial disease is a common event on first-generation TKI treatment because of its reduced BBB penetration. Crizotinib activity on brain tissue is, indeed, modest with an ORR of $18 \%$ and a time to progression of 7 months[29]. Approximately, during the first year of treatment with crizotinib, one third 
of patients develops metastases to the brain, which represents the only site of progression for many patients. Consequently, the metastases-directed approach has been attempted several times in clinical practice in order to prolong TKI benefit. A small study retrospectively evaluated the continuation of crizotinib treatment after radiotherapy for seven patients with ALK-rearranged NSCLC and isolated CNS progression. Four patients received WBRT and three patients underwent SRS. PFS2 was 5.5 months with a range of 2.6 to 17.2 months[30].

In this context, SBRT and SRS have assumed a pivotal role in the multidisciplinary approach of oligoprogressive oncogene-driven NSCLC, with the aim of improving not only survival but also quality of life through a reduced impact on neurocognitive functions. Although SRS is routinely used for the treatment of a limited number of brain metastases, studies have shown that this technique can also be successfully used for the management of more than 10 metastases and limited disease burden, without increasing late neurocognitive toxicity[31]. Robin et al evaluated 35 EGFR-mutated and ALKrearranged NSCLC patients with multiple brain metastases (median number of lesions: 6; range: 4-26) who underwent SRS, even in multiple courses, comparing doses delivered to hippocampus with SRS instead of WBRT or hippocampus-sparing WBRT. In patients treated with SRS on more than 10 brain metastases, the median dose delivered to hippocampus and to healthy brain was $1.2 \mathrm{~Gy}$ and $0.8 \mathrm{~Gy}$, respectively, significantly lower than the doses delivered with a pancencephalic treatment, even if optimized to reduce the dose to the hippocampus itself. Median survival from diagnosis of encephalic metastases was 3.0 years (4.2 years for ALK-rearranged NSCLC and 2.4 years for EGRF-mutated NSCLC). Survival was comparable regardless of number of radiosurgery courses, number of brain metastases treated in total, or number of brain metastases treated in a single radiosurgery session. Mortality related to intracranial progression was 26\%[32].

Before the advent of next-generation ALK TKIs, metastases-directed approach was recommended after crizotinib failure in order to prolong TKI treatment period as long as possible. However, the role and the correct timing for LATs became less clear after the introduction of innovative ALK inhibitors which have higher efficacy against common crizotinib resistance mutations and growing CNS activity.

Analyzing patients with CNS progression during crizotinib treatment, Zhao et al reported longer intracranial time to progression in patients who received sequential treatment with a second ALK TKI compared with those treated beyond progression after radiotherapy $(\mathrm{P}=.003)[33]$.

In the phase I ASCEND-1 trial, evaluating the safety and efficacy of ceritinib, 95 of the 255 patients enrolled had brain metastases at baseline. Of these, 19 patients were treatment naïve, 11 received ceritinib combined with radiotherapy and 8 received ceritinib alone. ORR (36.4\% vs. 50\%) and DCR (72.7\% vs. $87.5 \%)$ showed no significant differences between the two treatment groups. The ASCEND-4 trial had similar results[34][35]. Likewise, in a pooled analysis of two studies (NP28761 and NP28673) with ALK-positive NSCLC patients who had previously received crizotinib, alectinib combined with radiotherapy did not demonstrated a significant advantage compared to alectinib alone. CNS ORR was not statistically different between patients with prior radiotherapy (35.8\%, $\mathrm{n}=95)$ and patients without prior radiotherapy $(58.5 \%, \mathrm{n}=41)[36]$.

Moreover, as previously discussed, Ni et al reported that patients treated with LAT at crizotinib progression achieved a PFS2 of 10 months, comparable to or even lower than the PFS of patients progressing to crizotinib and treated with next-generation ALK inhibitors such as ceritinib, alectinib, brigatinib and lorlatinib without LATs[37][38][39][26].

The "beyond progression" strategy and the use of LAT in case of oligoprogressive disease remain common also with 2nd generation ALK TKIs in 1st line setting, the current therapeutic standard. The landscape in which LAT is placed is characterized, however, by deeper intracranial efficacy and disease control because of the higher CNS penetration of newer generation ALK TKIs. In the global phase III ALEX trial, indeed, alectinib showed not only higher efficacy and better tolerability than crizotinib as first-line therapy, with a 
significant prolongation of median PFS (34.8 vs 10.9 months; HR, 0.43; 95\% CI, 0.32-0.58) but also an important CNS activity in terms of ORR (85.7\% vs $71.4 \%)$ and CNS progression incidence at 12 months (9.4\% vs $41.4 \%)$. Even if OS data are still immature, the 5-year OS rate is higher with alectinib (62.5\% vs $45.5 \%)[28][4][40]$.

Similarly, in the randomized phase III ALTA-1L trial, brigatinib demonstrated a longer median PFS (HR 0.48 [95\% CI, 0.35 to 0.66]; log-rank $P<.0001$; median, 24.0 vs 11.0 months) ORR ( $74 \%$ vs $62 \%$ ) and intracranial ORR ( $78 \%$ vs $26 \%$ ) compared to crizotinib, with superior tolerability and quality of life (QoL)[41]. More recently, in the eXalt3 trial, ensartinib demonstrated longer PFS (25.8 vs 12.7 months; HR, 0.51 [95\%CI, 0.35-0.72]; p < $0.0001)$, higher ORR ( $74 \%$ vs $67 \%)$, and deeper intracranial RR (64\% vs $21 \%)$ compared with crizotinib[42].

Initially the 3rd generation ALK TKI lorlatinib, characterized by high blood-brain barrier penetration[43] demonstrated important overall and CNS efficacy both in treatment-naïve and in patients progressed on crizotinib, second-generation ALK TKIs, or both, with greater efficacy in patients harboring secondary ALK resistance mutations[27][44][45]. More recently in the CROWN study, comparing lorlatinib to crizotinib in patients with previously untreated advanced ALK-positive NSCLC, the $82 \%$ ( $95 \%$ CI, 57 to 96 ) of patients treated with lorlatinib and $23 \%$ of patients treated with crizotinib (95\% CI, 5 to 54) had an intracranial response, respectively. At 12 months, the cumulative incidence of CNS progression as the first event was 3\% with lorlatinib and 33\% with crizotinib (HR, 0.06; 95\% CI, 0.02 to 0.18 ). The percentage of patients who were alive without CNS progression at 12 months was $96 \%$ (95\% CI, 91 to 98 ) with lorlatinib and $60 \%$ (95\% CI, 49 to 69 ) with crizotinib (hazard ratio, $0.07 ; 95 \%$ CI, 0.03 to 0.17 )[46].

These data of important central efficacy highlight that, although radiotherapy is a cost-effective technique, delaying LATs is a valuable possibility in case of next-generation TKIs availability, to ensure the best local control while preserving neurological function and quality of life.

In order to optimize decision-making in the management of CNS involvement, prognostic scales estimating survival for patients with brain metastases have been developed. The Graded Prognostic Assessment (GPA) score takes into account age, number of brain lesions, performance status and extent of extracranial disease to define prognosis, irrespective of tumor histology. This score has been updated including the primary tumor as a prognostic variable, with the development of the Diagnosis-Specific GPA (DSGPA). The same group recently published the Lung-mol GPA, which considers lung cancer molecular profile for the presence of EGFR mutations and ALK rearrangements. Survival definition has been further improved, with a median survival of 47 months for the best prognostic group[47].

In general, because of the limited evidence available, in case of oligoprogressive disease, irrespective of sites of progression, inclusion in clinical trials is preferred.

\section{Systemic treatment algorithm: waiting for a guide}

As already discussed, also in case of oligoprogressive disease, considering the availability of further systemic treatment options is crucial to recognize the most effective and safe therapeutic strategy. However, as well known, new generation ALK TKI selection and sequencing is still challenging because of the absence of head-to-head comparisons. As a matter of fact, $2^{\text {nd }}$ and $3^{\text {rd }}$ generation ALK TKIs with an approximately $50 \%$ reduction in the risk of progression or death compared with crizotinib and with an impressive intracranial activity, definitely put $1^{\text {st }}$ line crizotinib on the corner (Table 2)[28][4][41][48][40][35][46].

In the absence of direct comparative trials, selection requires a comprehensive evaluation of drug systemic activity, CNS efficacy, drug interaction, safety and tolerability. Each ALK inhibitor has, indeed, a different side-effect profile with potential specific 
toxicities: diarrhea, nausea, and emesis with ceritinib; constipation and myalgias with alectinib; early-onset pneumonitis with brigatinib; rash, transaminase elevation, pruritus and nausea with ensartinib, altered lipid levels, cognitive and mood effects with lorlatinib[28][4][41][48][40][35][46].

All these factors are paramount to define the best systemic treatment strategy among all the available effective options.

Following 'the-best-first' theory, lorlatinib could be considered as the preferred frontline TKI because of its higher activity in terms of PFS HR and CNS efficacy[5]. Preclinical and retrospective data demonstrated that sequential use of ALK TKIs could favor lorlatinib-resistant compound mutations, indicating that the most potent TKI used in $1^{\text {st }}$ line, might better prevent acquired resistance mechanisms [49][50].

On the other hand, the sequence strategy, that keeps 3rd generation TKI for subsequent lines, still remains a good option, considering lorlatinib toxicity profile, the good activity and manageability of $2^{\text {nd }}$ generation ALK TKIs and the absence of targeted therapies available in case of lorlatinib-resistance. In addition, frontline lorlatinib postprogression data are largely awaited since the acquired resistance mechanisms, paramount for defining the following treatment options, are not fully understood. In the attempt to define the most effective treatment algorithm, biomarkers predicting patients with potentially more aggressive disease or CNS-tropic ALK tumor biology would be helpful to better personalize treatment strategy. For now, although ALK TKIs are approved regardless any specific molecular alterations acquired at the time of disease progression, testing for resistance mutations is paramount to drive treatment choices because specific ALK resistance mechanisms can predict sensitivity to different ALK inhibitors. Intra-tyrosine acquired ALK mutations are the most common mechanism of resistance with $2^{\text {nd }}$ generation ALK TKIs, present in about $50 \%$ of cases. Among them, pG1202R is the most frequent, reported in more than $50 \%$ of patients, generally sensitive to $3^{\text {rd }}$ generation TKI[43]. Around $55 \%$ of patients who received lorlatinib developed two or more mutations, such as the most common L1196M/G1202R that confers high-level resistance to first-, second-, and third-generation ALK TKIs, supporting the concept of progressive stepwise genetic complexity due to the selective pressure of sequential TKIs[50]. In the other cases the development of acquired resistance is caused by off-target mechanisms such as bypass signaling, histological and/or phenotypical transformations[43][51]. A phase II prospective MASTER protocol (NCT03737994) is currently evaluating a genomic-driven therapeutic sequence in ALK-rearranged metastatic NSCLC who progressed on prior second generation ALK TKIs, based on tumor genotype at the time of disease progression[52]. Indeed, re-biopsy and molecular profiling could be particularly helpful to define a personalized treatment algorithm above all when the sites of progression are limited and the need to change systemic treatment or to associate a local therapy largely debatable[51].

When ALK TKI options are exhausted, in case of lorlatinib-refractory patients for example, apart from rare and exceptional cases, older TKIs are not effective and other targeted therapies are currently not available. Some promising molecules have been studied but results are still immature[53].

Platinum-based chemotherapy, mainly with pemetrexed, is still a valuable option of treatment[54]. The combination of carboplatin-paclitaxel-bevacizumab and atezolizumab represents, for now, the only treatment regimen with an immune checkpoint inhibitor demonstrating a significant efficacy in oncogene addicted patients with an objective responses $>50 \%[55]$. 
Table 2. Comparison of frontline phase III trials in advanced ALK-rearranged NSCLC patients.

\begin{tabular}{|c|c|c|c|c|c|c|c|c|c|c|c|c|}
\hline & \multicolumn{2}{|c|}{ PROFILE 1014 ${ }^{3}$} & \multicolumn{2}{|c|}{$\overline{\text { ALEX }^{11}}$} & \multicolumn{2}{|c|}{ ALTA-1L ${ }^{12}$} & \multicolumn{2}{|c|}{ eXalt3 ${ }^{13}$} & \multicolumn{2}{|c|}{ ASCEND-4 ${ }^{15}$} & \multicolumn{2}{|c|}{ CROWN $^{22}$} \\
\hline & Crizotinib & $\begin{array}{c}\text { Chemotherap } \\
y\end{array}$ & Alectinib & Crizotinib & Brigatinib & Crizotinib & Ensartinib & Crizotinib & Ceritinib & $\begin{array}{c}\text { Chemothera } \\
\text { py }\end{array}$ & Lorlatinib & Crizotinib \\
\hline ORR & $74 \%$ & $45 \%$ & $83 \%$ & $76 \%$ & $74 \%$ & $62 \%$ & $74 \%$ & $67 \%$ & $72 \cdot 5 \%$ & $26.7 \%$ & $76 \%$ & $58 \%$ \\
\hline mPFS (months) & 10.9 & 7 & 34.8 & 10.9 & 29.4 & 9.2 & 25.8 & 12.7 & $16 \cdot 6$ & 8.1 & NR & 9.3 \\
\hline PFS HR & \multicolumn{2}{|c|}{$0.45 ; 95 \%$ CI, $0.35-0.60$} & \multicolumn{2}{|c|}{$0.43 ; 95 \%$ CI $0.32-0.48$} & \multicolumn{2}{|c|}{$0.43 ; 95 \%$ CI, $0.31-0.61$} & \multicolumn{2}{|c|}{$0.51 ; 95 \%$ CI, $0.35-0.72$} & \multicolumn{2}{|c|}{$0.55 ; 95 \%$ CI $0 \cdot 42-0.73$} & \multicolumn{2}{|c|}{$0.28 ; 95 \%$ CI, $0.19-0.41$} \\
\hline $\begin{array}{l}\text { Intracranial } \\
\text { response rate }\end{array}$ & -- & -- & $81 \%$ & $50 \%$ & $78 \%$ & $26 \%$ & $63.6 \%$ & $21.1 \%$ & $72 \cdot 7 \%$ & $27.3 \%$ & $82 \%$ & $23 \%$ \\
\hline $\begin{array}{l}\text { Frequency of } \\
\text { dose reduction }\end{array}$ & -- & -- & $20 \%$ & $20 \%$ & $38 \%$ & $25 \%$ & $24 \%$ & $20 \%$ & $80 \%$ & $45 \%$ & $21 \%$ & $15 \%$ \\
\hline $\begin{array}{l}\text { Frequency of } \\
\text { discontinuation }\end{array}$ & $12 \%$ & $14 \%$ & $15 \%$ & $15 \%$ & $13 \%$ & $9 \%$ & $9 \%$ & $7 \%$ & $5 \%$ & $11 \%$ & $7 \%$ & $9 \%$ \\
\hline $\begin{array}{l}\text { Key adverse } \\
\text { events }\end{array}$ & $\begin{array}{c}\text { dision } \\
\text { disorders, } \\
\text { diarrhea, } \\
\text { nausea, } \\
\text { and edema }\end{array}$ & $\begin{array}{l}\text { nausea, } \\
\text { fatigue, } \\
\text { vomiting, } \\
\text { and } \\
\text { decreased } \\
\text { appetite }\end{array}$ & $\begin{array}{c}\text { myalgia, } \\
\text { increased } \\
\text { blood } \\
\text { bilirubin, } \\
\text { increased } \\
\text { ALT }\end{array}$ & $\begin{array}{c}\text { nausea, } \\
\text { diarrhea, and } \\
\text { vomiting }\end{array}$ & $\begin{array}{c}\text { ILD/pneu } \\
\text { monitis, } \\
\text { nausea, } \\
\text { CPK } \\
\text { increase, } \\
\text { ALT } \\
\text { increase, } \\
\text { lipase } \\
\text { increase }\end{array}$ & $\begin{array}{c}\text { nausea, } \\
\text { diarrhea, } \\
\text { edema }\end{array}$ & $\begin{array}{c}\text { Rash, } \\
\text { pruritus, } \\
\text { nausea, } \\
\text { pyrexia, } \\
\text { ALT and } \\
\text { AST } \\
\text { increase }\end{array}$ & $\begin{array}{l}\text { liver toxic } \\
\text { effects, } \\
\text { nausea, } \\
\text { edema, and } \\
\text { constipation }\end{array}$ & $\begin{array}{c}\text { diarrhea, } \\
\text { nausea, } \\
\text { vomiting, } \\
\text { AST and } \\
\text { ALT } \\
\text { increase }\end{array}$ & $\begin{array}{c}\text { nausea, } \\
\text { vomiting } \\
\text { and anemia }\end{array}$ & $\begin{array}{c}\text { Edema, } \\
\text { Hyperchole } \\
\text { sterolemia, } \\
\text { hypertrigly } \\
\text { ceridemia, } \\
\text { increased } \\
\text { weight, } \\
\text { neuropathy } \\
\text {, cognitive } \\
\text { effects, } \\
\text { speech } \\
\text { effects }\end{array}$ & $\begin{array}{l}\text { Diarrhea, vision } \\
\text { disorder, } \\
\text { vomiting, } \\
\text { increased alanine } \\
\text { aminotransferase } \\
\text { level, fatigue, } \\
\text { constipation, } \\
\text { increased } \\
\text { aspartate } \\
\text { aminotransferase } \\
\text { level, decreased } \\
\text { appetite, } \\
\text { dysgeusia, and } \\
\text { bradycardia }\end{array}$ \\
\hline
\end{tabular}

ORR, objective response rate; PFS, progression-free survival; NR, not reached; CNS, central nervous system; HR, hazard ratio; CI, confidence interval. 


\section{Clinical cases}

\subsection{Patient 1 (Figure 1)}

\section{Patient information and presentation}

LMT, a 56-years-old female.

Past medical history: systemic arterial hypertension, no first-degree history of cancer. Smoking history: former light smoker.

Presentation: patient presented to the oncology department in May 2011 after occasional finding of right pleural effusion during pre-surgical tests for thyroid nodes, general good clinical conditions (ECOG PS 0).

Metastatic NSCLC diagnosis

Contrast CT scan and 18FDG-PET/CT confirmed right pleural effusion and documented the presence of middle lobe mass, multiple right lower lobe nodes, pleural and mediastinal lymph nodes involvement. Histological examination of pleural biopsy: NSCLC, adenocarcinoma histotype. Biomarker tests: EGFR wild-type; EML4-ALK rearrangement.

Patient journey

Because of the absence of approved targeted treatment at that time, from October 2011 to February 2012 MLT was treated with first-line cisplatin $75 \mathrm{mg} / \mathrm{mq}$ + pemetrexed $500 \mathrm{mg} / \mathrm{mq}$ (6 cycles). Best response (BR): stable disease. In July 2013 thoracic and abdominal disease progression occurred (increase of lung parenchymal lesions, carcinomatous lymphangitis, extension in pleural involvement, axillary and abdominal lymphadenopathies). MLT was started on ceritinib, taking part in a clinical trial. BR: partial response of disease. In May 2015 the CT scan recorded a new single encephalic lesion at right temporal lobe. Multidisciplinary evaluation: in consideration of the oligoprogressive pattern, the patient underwent exeresis of the right temporal lesion while maintaining ceritinib treatment. Histologic report of brain tissue: lung adenocarcinoma. Biomarker tests: EML4ALK rearrangement, no evidence of ALK resistant mutations. Treatment with ceritinib, initially well tolerated, was definitively discontinued in April 2016, after progressive dosage reduction, for refractory G3 transaminases elevation. The patient continued with a close clinical and radiological monitoring. In July 2016 because of a widespread encephalic progression (new left frontal lobe and left parietal lobe lesions, dimensional increase of previously treated right temporal, left parietal and right parietal lobe metastases) WBRT was performed ( $30 \mathrm{~Gy} / 10 \mathrm{fr})$, after multidisciplinary evaluation, with a good radiological and clinical response to treatment. Few months later (October 2016) because of abdominal lymph nodal progression of disease a new systemic treatment with brigatinib $180 \mathrm{mg} / \mathrm{die}$ in the Early Access Program (EAP) was prescribed. BR: partial response (regression of almost all encephalic lesions and partial regression of abdominal lymph nodes). In June 2018, after almost two years from treatment start, because of the appearance of a new left frontal-parietal metastasis and the increase of the right temporal one, SRS was perfomed (18 Gy each). Disease remained stable until October 2020 when a new disseminated encephalic progression occurred. Patient was still in good clinical condition, ECOG PS 1, with only mild cognitive impairment after WBRT. Fourth-line treatment with lorlatinib 100 $\mathrm{mg} /$ die in EAP was started.

LMT is alive and lorlatinib treatment ongoing (last follow up in November 2021). 


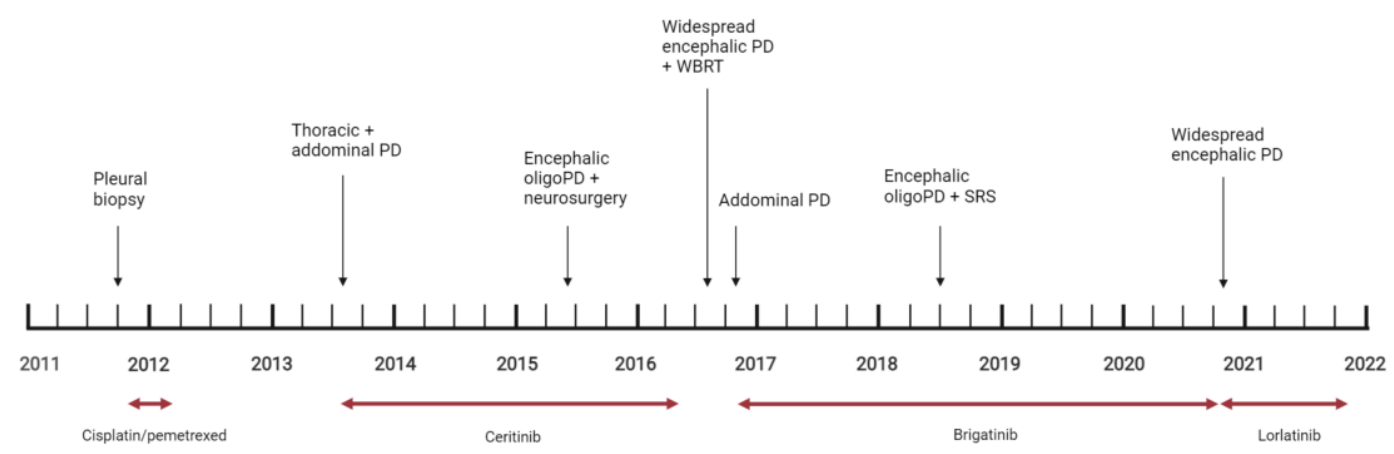

Figure 1. Patient 1 oncological history.

PD: progressive disease; oligoPD: oligoprogression; WBRT: whole brain radiotherapy; SRS: stereotactic radiosurgery.

\subsection{Patient 2 (Figure 2)}

\section{Patient information and presentation}

RC, a 55-years-old male.

Past medical history: no major illness.

Smoking history: former smoker (20 p/y).

Presentation: patient presented to the oncology department in February 2018 after a history of cough unresponsive to antibiotic and corticosteroid therapy and a chest CT finding of a $17 \mathrm{~mm}$ nodule at the right lung base, along with right hilar and mediastinal adenopathies. General good clinical conditions (ECOG PS 0).

\section{Metastatic NSCLC diagnosis}

Contrast CT scan and 18FDG-PET/CT confirmed the presence of pulmonary nodule, hilar and mediastinal adenopathies and showed left adrenal gland involvement and widespread bones metastases. Analysis of the cytological sample obtained by bronchoscopy: NSCLC, adenocarcinoma histotype. Biomarker tests: EGFR wild-type; ROS1 not rearranged; EML4-ALK rearrangement; PD-L1 TPS 5\%

Patient journey

In March 2018, the patient started treatment with crizotinib $250 \mathrm{mg}$ bid. BR: progression of disease (multiple brain metastases and meningeal dissemination, thoracic progression). RC was started on alectinib $600 \mathrm{mg}$ bid. BR: partial response of disease. Treatment was overall well tolerated. In April 2020, after two years of alectinib, a widespread encephalic and hepatic progression occurred; taking into account patient's asymptomaticity and the availability of additional targeted therapies, WBRT was not performed and the patient started treatment with lorlatinib $100 \mathrm{mg} / \mathrm{die}$. BR: partial response of disease. The treatment was initially well tolerated, but due to the onset of speech impediment, psychomotor slowing and memory impairment, a reduction in the dosage of $75 \mathrm{mg} /$ day was indicated. Disease remained stable until March 2021 when CT scan showed a new hepatic progression of disease. Multidisciplinary evaluation: in consideration of oligoprogressive pattern, the patient underwent liver biopsy and subsequent microwave thermoablation of the lesion. Histologic report of hepatic tissue: lung adenocarcinoma. Biomarker tests: EML4-ALK rearrangement, resistance mutations not reported.

$\mathrm{RC}$ is alive and lorlatinib treatment ongoing (last follow up in November 2021).

These two patients' stories are an illustrative example of how proper management of oligoprogression can prolong TKIs benefit in oncogene-addicted NSCLC, significantly improving survival and quality of life. 


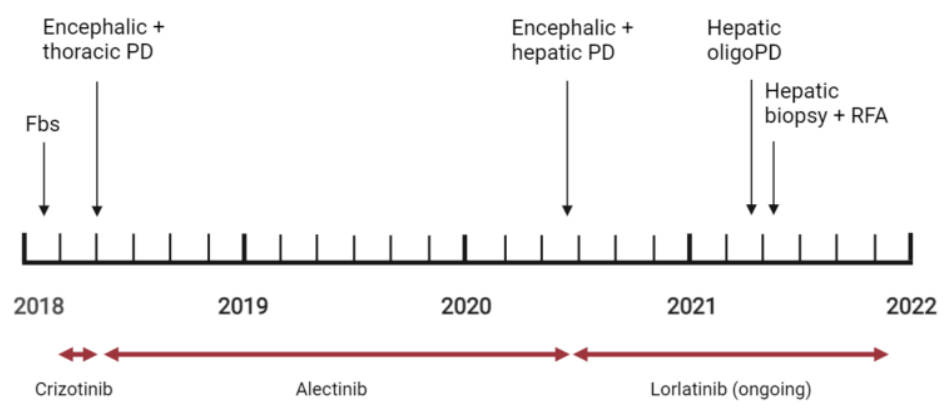

Figure 1. Patient 2 oncological history.

Fbs: fibrobronchoscopy; PD: progressive disease; oligoPD: oligoprogression; RFA: radiofrequency ablation.

\section{Perspectives and conclusion}

All together, these data confirm the success of treatment development for $A L K$ rearranged NSCLC patients and the fast translation of these progresses into remarkable clinical outcome improvements. At the same time, they raise the questions about how to maximize the benefit potentially deriving from the expanding plethora of effective options (systemic and local ones). Retrospective results certainly justify the attempt of prolonging targeted therapies benefit by associating local treatment in case of oligoprogression, above all when no more targeted therapies are available. The volume and the location of progressive site, the toxicities related to the different approaches (systemic therapies or ablative ones), patient's general conditions, age, comorbidities, and, finally, multidisciplinary discussion are undoubtedly paramount in the decision, particularly in a setting in which prospective data are lacking[56]. Several trials are ongoing in order to compare different treatment approach in case of oligoprogressive disease (Table 3) and even if completing enrollment is not easy, is now paramount. These results, indeed, together with the identification of specific biomarkers predicting benefit from local therapy or widespread progression are potentially the key to recognize the best treatment approach for every oligoprogressive ALK rearranged lung cancer patient.

Table 3. Main ongoing clinical trials in oligoprogressive NSCLC.

\begin{tabular}{|c|c|c|c|c|c|c|c|c|}
\hline Trial & $\begin{array}{c}\text { Active } \\
\text { Comparator } \\
\text { Arm }\end{array}$ & $\begin{array}{c}\text { Experimental } \\
\text { Arm }\end{array}$ & $\begin{array}{c}\text { Tumor } \\
\text { type }\end{array}$ & $\begin{array}{l}\text { Molecular } \\
\text { selection }\end{array}$ & $\begin{array}{c}\text { Definition of } \\
\text { oligroprogression }\end{array}$ & $\begin{array}{l}\text { Primary } \\
\text { endpoint }\end{array}$ & Phase & Status \\
\hline $\begin{array}{l}\text { NCT02756793 } \\
\text { (STOP trial) }\end{array}$ & $\begin{array}{l}\text { SoC (Continue } \\
\text { with current } \\
\text { systemic } \\
\text { agent(s)/ } \\
\text { Observation/ } \\
\text { Switch to next- } \\
\text { line treatment }\end{array}$ & $\begin{array}{c}\text { SABR + } \\
\text { continuation of } \\
\text { current systemic } \\
\text { agents }\end{array}$ & NSCLC & -- & $\begin{array}{c}\text { Maximum } 3 \\
\text { progressing } \\
\text { metastases in any } \\
\text { single organ } \\
\text { system and the } \\
\text { total number of } \\
\text { metastases must } \\
\text { be } 5 \text { or less }\end{array}$ & PFS & -- & $\begin{array}{l}\text { Active, not } \\
\text { recruiting }\end{array}$ \\
\hline NCT04519983 & -- & $\begin{array}{c}\text { Upfront TKI + } \\
\text { Salvage SRT }\end{array}$ & NSCLC & EGFR & $\begin{array}{l}\text { intracranial oligo- } \\
\text { progression }\end{array}$ & iORR & 2 & $\begin{array}{l}\text { Not yet } \\
\text { recruiting }\end{array}$ \\
\hline $\begin{array}{c}\text { NCT04405401 } \\
\text { (SUPPRESS- } \\
\text { NSCLC) }\end{array}$ & $\begin{array}{l}\text { SoC (Switch to } \\
\text { subsequent } \\
\text { systemic } \\
\text { therapy line/ } \\
\text { BSC/ continue } \\
\text { current systemic } \\
\text { line) }\end{array}$ & $\begin{array}{c}\text { SABR to } \\
\text { oligoprogressive } \\
\text { lesions + } \\
\text { continue current } \\
\text { systemic therapy }\end{array}$ & NSCLC & -- & $\begin{array}{l}\text { 1-5 extracranial } \\
\text { lesions }\end{array}$ & PFS, OS & 2 & Recruiting \\
\hline
\end{tabular}




\begin{tabular}{|c|c|c|c|c|c|c|c|c|}
\hline $\begin{array}{c}\text { NCT03256981 } \\
\text { (HALT) }\end{array}$ & $\begin{array}{l}\text { Continued TKI } \\
\text { therapy alone }\end{array}$ & $\begin{array}{c}\text { SBRT and } \\
\text { continued TKI } \\
\text { therapy }\end{array}$ & NSCLC & $\begin{array}{c}\text { actionable } \\
\text { mutation treat } \\
\text { ed with TKI }\end{array}$ & $\begin{array}{c}\leq 3 \text { extracranial } \\
\text { sites of } \\
\text { progressive } \\
\text { disease }\end{array}$ & PFS & $2 / 3$ & Recruiting \\
\hline NCT03808662 & SoC & SBRT & $\begin{array}{c}\text { NSCLC, } \\
\text { breast } \\
\text { cancer }\end{array}$ & $\begin{array}{c}\text { Non oncogene } \\
\text { addicted } \\
\text { cohort }+ \\
\text { oncogene } \\
\text { addicted } \\
\text { cohort }\end{array}$ & $\begin{array}{c}\text { 1-5 oligo- } \\
\text { progressive } \\
\text { lesions }\end{array}$ & PFS & 2 & Recruiting \\
\hline
\end{tabular}

SoC: Stadard of Care; NSCLC: non-small cell lung cancer, PFS: progression-free survival, iORR: Intracranial objective response rate; BSC: best supportive care; OS: overall survival

\begin{abstract}
Author Contributions: Conceptualization, all authors; writing-original draft preparation, C.P., M.D.F, F.J., M.L.R; writing-review and editing, all authors.

Funding: This research received no external funding.

Conflicts of Interest: S.N., personal fees (as speaker bureau or advisor) from Eli Lilly, MSD, Roche, BMS, Takeda, Pfizer, Astra Zeneca and Boehringer Ingelheim; M.L.R., personal fees (as speaker bureau or consultant) from Eli Lilly, MSD; the other authors declare no conflict of interest.
\end{abstract}

\title{
Bibliography
}

1. Shaw, A.T.; Yeap, B.Y.; Mino-Kenudson, M.; Digumarthy, S.R.; Costa, D.B.; Heist, R.S.; Solomon, B.; Stubbs, H.; Admane, S.; McDermott, U.; et al. Clinical Features and Outcome of Patients With Non-Small-Cell Lung Cancer Who Harbor EML4-ALK. J. Clin. Oncol. 2009, 27, 4247-4253, doi:10.1200/JCO.2009.22.6993.

2. Hallberg, B.; Palmer, R.H. Mechanistic insight into ALK receptor tyrosine kinase in human cancer biology. Nat. Rev. Cancer 2013, 13, 685-700, doi:10.1038/nrc3580.

3. Solomon, B.J.; Mok, T.; Kim, D.-W.; Wu, Y.-L.; Nakagawa, K.; Mekhail, T.; Felip, E.; Cappuzzo, F.; Paolini, J.; Usari, T.; et al. First-line crizotinib versus chemotherapy in ALK-positive lung cancer. N. Engl. J. Med. 2014, 371, 2167-77, doi:10.1056/NEJMoa1408440.

4. Mok, T.; Camidge, D.R.; Gadgeel, S.M.; Rosell, R.; Dziadziuszko, R.; Kim, D.-W.; Pérol, M.; Ou, S.-H.I.; Ahn, J.S.; Shaw, A.T.; et al. Updated overall survival and final progression-free survival data for patients with treatment-naive advanced ALK-positive non-small-cell lung cancer in the ALEX study. Ann. Oncol. 2020, 31, 1056-1064, doi:https://doi.org/10.1016/j.annonc.2020.04.478.

5. Elsayed, M.; Christopoulos, P. Therapeutic Sequencing in ALK(+) NSCLC. Pharmaceuticals (Basel). 2021, 14, 80, doi:10.3390/ph14020080.

6. Hellman, S.; Weichselbaum, R.R. Oligometastases. J. Clin. Oncol. 1995, 13, 8-10, doi:10.1200/JCO.1995.13.1.8.

7. Dingemans, A.-M.C.; Hendriks, L.E.L.; Berghmans, T.; Levy, A.; Hasan, B.; Faivre-Finn, C.; Giaj-Levra, M.; Giaj-Levra, N.; Girard, N.; Greillier, L.; et al. Definition of Synchronous Oligometastatic Non-Small Cell Lung Cancer-A Consensus Report. J. Thorac. Oncol. 2019, 14, 2109-2119, doi:https://doi.org/10.1016/j.jtho.2019.07.025.

8. Gomez, D.R.; Blumenschein, G.R.; Lee, J.J.; Hernandez, M.; Ye, R.; Camidge, D.R.; Doebele, R.C.; Skoulidis, F.; Gaspar, L.E.; Gibbons, D.L.; et al. Local consolidative therapy versus maintenance therapy or observation for patients with oligometastatic non-small-cell lung cancer without progression after first-line systemic therapy: a multicentre, randomised, controlled, phase 2 study. Lancet Oncol. 2016, 17, 1672-1682, doi:https://doi.org/10.1016/S1470-2045(16)30532-0.

9. Weickhardt, A.J.; Scheier, B.; Burke, J.M.; Gan, G.; Lu, X.; Bunn, P.A.; Aisner, D.L.; Gaspar, L.E.; Kavanagh, B.D.; Doebele, R.C.; et al. Local Ablative Therapy of Oligoprogressive Disease Prolongs Disease Control by Tyrosine Kinase Inhibitors in OncogeneAddicted Non-Small-Cell Lung Cancer. J. Thorac. Oncol. 2012, 7, 1807-1814, doi:https://doi.org/10.1097/JTO.0b013e3182745948.

10. Togashi, Y.; Masago, K.; Fukudo, M.; Terada, T.; Fujita, S.; Irisa, K.; Sakamori, Y.; Kim, Y.H.; Mio, T.; Inui, K.; et al. Cerebrospinal Fluid Concentration of Erlotinib and its Active Metabolite OSI-420 in Patients with Central Nervous System Metastases of Nonsmall Cell Lung Cancer. J. Thorac. Oncol. 2010, 5, 950-955, doi:https://doi.org/10.1097/JTO.0b013e3181e2138b.

11. Costa, D.B.; Kobayashi, S.; Pandya, S.S.; Yeo, W.-L.; Shen, Z.; Tan, W.; Wilner, K.D. CSF Concentration of the Anaplastic Lymphoma Kinase Inhibitor Crizotinib. J. Clin. Oncol. 2011, 29, e443-e445, doi:10.1200/JCO.2010.34.1313.

12. Campo, M.; Al-Halabi, H.; Khandekar, M.; Shaw, A.T.; Sequist, L. V; Willers, H. Integration of Stereotactic Body Radiation Therapy With Tyrosine Kinase Inhibitors in Stage IV Oncogene-Driven Lung Cancer. Oncologist 2016, 21, 964-973, doi:https://doi.org/10.1634/theoncologist.2015-0508.

13. Lardinois, D.; Weder, W.; Hany, T.F.; Kamel, E.M.; Korom, S.; Seifert, B.; von Schulthess, G.K.; Steinert, H.C. Staging of NonSmall-Cell Lung Cancer with Integrated Positron-Emission Tomography and Computed Tomography. N. Engl. J. Med. 2003, 348, 2500-2507, doi:10.1056/NEJMoa022136. 
14. Ng, T.L.; Morgan, R.L.; Patil, T.; Barón, A.E.; Smith, D.E.; Ross Camidge, D. Detection of oligoprogressive disease in oncogeneaddicted non-small cell lung cancer using PET/CT versus CT in patients receiving a tyrosine kinase inhibitor. Lung Cancer 2018, 126, 112-118, doi:https://doi.org/10.1016/j.lungcan.2018.10.023.

15. Kerner, G.S.M.A.; Koole, M.J.B.; Bongaerts, A.H.H.; Pruim, J.; Groen, H.J.M.; Consortium, C.A.F. Total Body Metabolic Tumor Response in ALK Positive Non-Small Cell Lung Cancer Patients Treated with ALK Inhibition. PLoS One 2016, 11, e0149955.

16. Juan, O.; Popat, S. Ablative Therapy for Oligometastatic Non-Small Cell Lung Cancer. Clin. Lung Cancer 2017, 18, 595-606, doi:https://doi.org/10.1016/j.cllc.2017.03.002.

17. Cheung, P. Stereotactic body radiotherapy for oligoprogressive cancer. Br. J. Radiol. 2016, 89, 1-6, doi:10.1259/bjr.20160251.

18. Dai, Y.; Wei, Q.; Schwager, C.; Moustafa, M.; Zhou, C.; Lipson, K.E.; Weichert, W.; Debus, J.; Abdollahi, A. Synergistic effects of crizotinib and radiotherapy in experimental EML4-ALK fusion positive lung cancer. Radiother. Oncol. 2015, 114, 173-181, doi:https://doi.org/10.1016/j.radonc.2014.12.009.

19. Sun, Y.; Nowak, K.A.; Zaorsky, N.G.; Winchester, C.-L.; Dalal, K.; Giacalone, N.J.; Liu, N.; Werner-Wasik, M.; Wasik, M.A.; Dicker, A.P.; et al. ALK Inhibitor PF02341066 (Crizotinib) Increases Sensitivity to Radiation in Non-Small Cell Lung Cancer Expressing EML4-ALK. Mol. Cancer Ther. 2013, 12, 696 LP - 704, doi:10.1158/1535-7163.MCT-12-0868.

20. Dai, Y.; Wei, Q.; Schwager, C.; Hanne, J.; Zhou, C.; Herfarth, K.; Rieken, S.; Lipson, K.E.; Debus, J.; Abdollahi, A. Oncogene addiction and radiation oncology: effect of radiotherapy with photons and carbon ions in ALK-EML4 translocated NSCLC. Radiat. Oncol. 2018, 13, 1, doi:10.1186/s13014-017-0947-0.

21. FLESCHUTZ, K.; WALTER, L.; LEISTNER, R.; HEINZERLING, L. ALK Inhibitors Do Not Increase Sensitivity to Radiation in EML4-ALK Non-small Cell Lung Cancer. Anticancer Res. 2020, 40, 4937 LP - 4946, doi:10.21873/anticanres.14497.

22. Gan, G.N.; Weickhardt, A.J.; Scheier, B.; Doebele, R.C.; Gaspar, L.E.; Kavanagh, B.D.; Camidge, D.R. Stereotactic Radiation Therapy can Safely and Durably Control Sites of Extra-Central Nervous System Oligoprogressive Disease in Anaplastic Lymphoma Kinase-Positive Lung Cancer Patients Receiving Crizotinib. Int. J. Radiat. Oncol. 2014, 88, 892-898, doi:https://doi.org/10.1016/j.ijrobp.2013.11.010.

23. Liu, J.; Cui, S.; Pan, F.; Ni, Y.; Zhong, H.; Xiong, L.; Jin, B.; Chu, T.; Gu, A.; Jiang, L. Feasibility of continuing crizotinib therapy after RECIST-PD in advanced non-small cell lung cancer patients with ALK/ROS-1 mutations. J. Cancer 2018, 9, 1863-1869, doi:10.7150/jca.24950.

24. Kroeze, S.G.C.; Schaule, J.; Fritz, C.; Kaul, D.; Blanck, O.; Kahl, K.H.; Roeder, F.; Siva, S.; Verhoeff, J.J.C.; Adebahr, S.; et al. Metastasis directed stereotactic radiotherapy in NSCLC patients progressing under targeted- or immunotherapy: efficacy and safety reporting from the 'TOaSTT' database. Radiat. Oncol. 2021, 16, 4, doi:10.1186/s13014-020-01730-0.

25. Borghetti, P.; Bonù, M.L.; Giubbolini, R.; Levra, N.G.; Mazzola, R.; Perna, M.; Visani, L.; Meacci, F.; Taraborrelli, M.; Triggiani, L.; et al. Concomitant radiotherapy and TKI in metastatic EGFR- or ALK-mutated non-small cell lung cancer: a multicentric analysis on behalf of AIRO lung cancer study group. Radiol. Med. 2019, 124, 662-670, doi:10.1007/s11547-019-00999-w.

26. Ni, J.; Li, G.; Yang, X.; Chu, L.; Wang, J.; Li, Y.; Zou, L.; Li, Y.; Xie, C.; Zhu, Z. Optimal timing and clinical value of radiotherapy in advanced ALK-rearranged non-small cell lung cancer with or without baseline brain metastases: implications from pattern of failure analyses. Radiat. Oncol. 2019, 14, 44, doi:10.1186/s13014-019-1240-1.

27. Solomon, B.J.; Besse, B.; Bauer, T.M.; Felip, E.; Soo, R.A.; Camidge, D.R.; Chiari, R.; Bearz, A.; Lin, C.C.; Gadgeel, S.M.; et al. Lorlatinib in patients with ALK-positive non-small-cell lung cancer: results from a global phase 2 study. Lancet Oncol. 2018, doi:10.1016/S1470-2045(18)30649-1.

28. Peters, S.; Camidge, D.R.; Shaw, A.T.; Gadgeel, S.; Ahn, J.S.; Kim, D.-W.; Ou, S.-H.I.; Pérol, M.; Dziadziuszko, R.; Rosell, R.; et al. Alectinib versus Crizotinib in Untreated ALK-Positive Non-Small-Cell Lung Cancer. N. Engl. J. Med. 2017, 377, 829-838, doi:10.1056/NEJMoa1704795.

29. Costa, D.B.; Shaw, A.T.; Ou, S.H.I.; Solomon, B.J.; Riely, G.J.; Ahn, M.J.; Zhou, C.; Martin Shreeve, S.; Selaru, P.; Polli, A.; et al. Clinical experience with crizotinib in patients with advanced ALK-rearranged non-small-cell lung cancer and brain metastases. J. Clin. Oncol. 2015, 33, 1881-1888, doi:10.1200/JCO.2014.59.0539.

30. Takeda, M.; Okamoto, I.; Nakagawa, K. Clinical Impact of Continued Crizotinib Administration after Isolated Central Nervous System Progression in Patients with Lung Cancer Positive for ALK Rearrangement. J. Thorac. Oncol. 2013, 8, 654-657, doi:https://doi.org/10.1097/JTO.0b013e31828c28e7.

31. Yamamoto, M.; Serizawa, T.; Higuchi, Y.; Sato, Y.; Kawagishi, J.; Yamanaka, K.; Shuto, T.; Akabane, A.; Jokura, H.; Yomo, S.; et al. A Multi-institutional Prospective Observational Study of Stereotactic Radiosurgery for Patients With Multiple Brain Metastases (JLGK0901 Study Update): Irradiation-related Complications and Long-term Maintenance of Mini-Mental State Examination Scores. Int. J. Radiat. Oncol. 2017, 99, 31-40, doi:https://doi.org/10.1016/j.ijrobp.2017.04.037.

32. Robin, T.P.; Camidge, D.R.; Stuhr, K.; Nath, S.K.; Breeze, R.E.; Pacheco, J.M.; Liu, A.K.; Gaspar, L.E.; Purcell, W.T.; Doebele, R.C.; et al. Excellent Outcomes with Radiosurgery for Multiple Brain Metastases in ALK and EGFR Driven Non-Small Cell Lung Cancer. J. Thorac. Oncol. 2018, 13, 715-720, doi:https://doi.org/10.1016/j.jtho.2017.12.006.

33. Zhao, Y.; Zhang, B.; Wang, S.; Qiao, R.; Xu, J.; Zhang, L.; Zhang, Y.; Han, B. Management of Central Nervous System Metastases in Patients With Advanced Anaplastic Lymphoma Kinase-Rearranged Non\&\#x2013;Small-Cell Lung Cancer During Crizotinib Treatment. Clin. Lung Cancer 2019, 20, e631-e637, doi:10.1016/j.cllc.2019.06.013.

34. Kim, D.-W.; Mehra, R.; Tan, D.S.W.; Felip, E.; Chow, L.Q.M.; Camidge, D.R.; Vansteenkiste, J.; Sharma, S.; De Pas, T.; Riely, G.J.; et al. Activity and safety of ceritinib in patients with ALK-rearranged non-small-cell lung cancer (ASCEND-1): updated results from the multicentre, open-label, phase 1 trial. Lancet Oncol. 2016, 17, 452-463, doi:https://doi.org/10.1016/S1470-2045(15)006142. 
35. Soria, J.-C.; Tan, D.S.W.; Chiari, R.; Wu, Y.-L.; Paz-Ares, L.; Wolf, J.; Geater, S.L.; Orlov, S.; Cortinovis, D.; Yu, C.-J.; et al. Firstline ceritinib versus platinum-based chemotherapy in advanced ALK-rearranged non-small-cell lung cancer (ASCEND-4): a randomised, open-label, phase 3 study. Lancet 2017, 389, 917-929, doi:https://doi.org/10.1016/S0140-6736(17)30123-X.

36. Gadgeel, S.M.; Shaw, A.T.; Govindan, R.; Gandhi, L.; Socinski, M.A.; Camidge, D.R.; De Petris, L.; Kim, D.-W.; Chiappori, A.; Moro-Sibilot, D.L.; et al. Pooled Analysis of CNS Response to Alectinib in Two Studies of Pretreated Patients With ALK-Positive Non-Small-Cell Lung Cancer. J. Clin. Oncol. 2016, 34, 4079-4085, doi:10.1200/JCO.2016.68.4639.

37. Shaw, A.T.; Kim, T.M.; Crinò, L.; Gridelli, C.; Kiura, K.; Liu, G.; Novello, S.; Bearz, A.; Gautschi, O.; Mok, T.; et al. Ceritinib versus chemotherapy in patients with ALK-rearranged non-small-cell lung cancer previously given chemotherapy and crizotinib (ASCEND-5): a randomised, controlled, open-label, phase 3 trial. Lancet Oncol. 2017, 18, 874-886, doi:10.1016/S14702045(17)30339-X.

38. Novello, S.; Mazières, J.; Oh, I.J.; de Castro, J.; Migliorino, M.R.; Helland, A.; Dziadziuszko, R.; Griesinger, F.; Kotb, A.; Zeaiter, A.; et al. Alectinib versus chemotherapy in crizotinibpretreated anaplastic lymphoma kinase (ALK)-positive non-small-cell lung cancer: Results from the phase III ALUR study. Ann. Oncol. 2018, doi:10.1093/annonc/mdy121.

39. Kim, D.-W.; Tiseo, M.; Ahn, M.-J.; Reckamp, K.L.; Hansen, K.H.; Kim, S.-W.; Huber, R.M.; West, H.L.; Groen, H.J.M.; Hochmair, M.J.; et al. Brigatinib in Patients With Crizotinib-Refractory Anaplastic Lymphoma Kinase-Positive Non-Small-Cell Lung Cancer: A Randomized, Multicenter Phase II Trial. J. Clin. Oncol. 2017, 35, 2490-2498, doi:10.1200/JCO.2016.71.5904.

40. Gadgeel, S.; Peters, S.; Mok, T.; Shaw, A.T.; Kim, D.W.; Ou, S.I.; Pérol, M.; Wrona, A.; Novello, S.; Rosell, R.; et al. Alectinib versus crizotinib in treatment-naive anaplastic lymphoma kinase-positive (ALK+) non-small-cell lung cancer: CNS efficacy results from the ALEX study. Ann. Oncol. Off. J. Eur. Soc. Med. Oncol. 2018, 29, 2214-2222, doi:10.1093/annonc/mdy405.

41. Camidge, D.R.; Kim, H.R.; Ahn, M.-J.; Yang, J.C.H.; Han, J.-Y.; Hochmair, M.J.; Lee, K.H.; Delmonte, A.; García Campelo, M.R.; Kim, D.-W.; et al. Brigatinib Versus Crizotinib in Advanced ALK Inhibitor-Naive ALK-Positive Non-Small Cell Lung Cancer: Second Interim Analysis of the Phase III ALTA-1L Trial. J. Clin. Oncol. 2020, 38, 3592-3603, doi:10.1200/JCO.20.00505.

42. Selvaggi, G.; Wakelee, H.A.; Mok, T.; Wu, Y.-L.; Reck, M.; Chiappori, A.; Cicin, I.; Lee, D.H.; Breder, V.; Fan, Y.; et al. ID:1882 Phase III Randomized Study of Ensartinib vs Crizotinib in Anaplastic Lymphoma Kinase (ALK) POSITIVE NSCLC Patients: eXalt3. J. Thorac. Oncol. 2020, 15, e41-e42, doi:10.1016/j.jtho.2020.08.003.

43. Gainor, J.F.; Dardaei, L.; Yoda, S.; Friboulet, L.; Leshchiner, I.; Katayama, R.; Dagogo-Jack, I.; Gadgeel, S.; Schultz, K.; Singh, M.; et al. Molecular mechanisms of resistance to first- and second-generation ALK inhibitors in ALK -rearranged lung cancer. Cancer Discov. 2016, 6, 1118-1133, doi:10.1158/2159-8290.CD-16-0596.

44. Dagogo-Jack, I.; Oxnard, G.R.; Fink, J.; Diubaldi, G.; Helms, C.; Gainor, J.F.; Rabin, M.S.; Heist, R.S.; Lin, J.J.; Ackil, J.; et al. A phase II study of lorlatinib in patients (pts) with ALK-positive (ALK+) lung cancer with brain-only progression. J. Clin. Oncol. 2020, 38, 9595, doi:10.1200/JCO.2020.38.15_suppl.9595.

45. Bauer, T.M.; Shaw, A.T.; Johnson, M.L.; Navarro, A.; Gainor, J.F.; Thurm, H.; Pithavala, Y.K.; Abbattista, A.; Peltz, G.; Felip, E. Brain Penetration of Lorlatinib: Cumulative Incidences of CNS and Non-CNS Progression with Lorlatinib in Patients with Previously Treated ALK-Positive Non-Small-Cell Lung Cancer. Target. Oncol. 2020, 15, 55-65, doi:10.1007/s11523-020-00702-4.

46. Shaw, A.T.; Bauer, T.M.; de Marinis, F.; Felip, E.; Goto, Y.; Liu, G.; Mazieres, J.; Kim, D.-W.; Mok, T.; Polli, A.; et al. First-Line Lorlatinib or Crizotinib in Advanced ALK -Positive Lung Cancer . N. Engl. J. Med. 2020, 383, 2018-2029, doi:10.1056/nejmoa2027187.

47. Sperduto, P.W.; Yang, T.J.; Beal, K.; Pan, H.; Brown, P.D.; Bangdiwala, A.; Shanley, R.; Yeh, N.; Gaspar, L.E.; Braunstein, S.; et al. Estimating Survival in Patients With Lung Cancer and Brain Metastases: An Update of the Graded Prognostic Assessment for Lung Cancer Using Molecular Markers (Lung-molGPA). JAMA Oncol. 2017, 3, 827-831, doi:10.1001/jamaoncol.2016.3834.

48. Horn, L.; Wang, Z.; Wu, G.; Poddubskaya, E.; Mok, T.; Reck, M.; Wakelee, H.; Chiappori, A.A.; Lee, D.H.; Breder, V.; et al. Ensartinib vs Crizotinib for Patients With Anaplastic Lymphoma Kinase-Positive Non-Small Cell Lung Cancer: A Randomized Clinical Trial. JAMA Oncol. 2021, e213523, doi:10.1001/jamaoncol.2021.3523.

49. Nagasaka, M.; Ou, S.-H.I. Lorlatinib Should Be Considered as the Preferred First-Line Option in Patients With Advanced $<\mathrm{em}>$ ALK</em>-Rearranged NSCLC. J. Thorac. Oncol. 2021, 16, 532-536, doi:10.1016/j.jtho.2020.12.021.

50. Yoda, S.; Lin, J.J.; Lawrence, M.S.; Burke, B.J.; Friboulet, L.; Langenbucher, A.; Dardaei, L.; Prutisto-Chang, K.; Dagogo-Jack, I.; Timofeevski, S.; et al. Sequential ALK Inhibitors Can Select for Lorlatinib-Resistant Compound ALK Mutations in ALK-Positive Lung Cancer. Cancer Discov. 2018, 8, 714-729, doi:10.1158/2159-8290.CD-17-1256.

51. Dagogo-Jack, I.; Rooney, M.; Lin, J.J.; Nagy, R.J.; Yeap, B.Y.; Hubbeling, H.; Chin, E.; Ackil, J.; Farago, A.F.; Hata, A.N.; et al. Treatment with Next-Generation ALK Inhibitors Fuels Plasma ALK Mutation Diversity. Clin. Cancer Res. 2019, 25, 6662-6670, doi:10.1158/1078-0432.CCR-19-1436.

52. Hu, C.; Dignam, J.J. Biomarker-Driven Oncology Clinical Trials: Key Design Elements, Types, Features, and Practical Considerations. JCO Precis. Oncol. 2019, 3, PO.19.00086, doi:10.1200/PO.19.00086.

53. Murray, B.W.; Zhai, D.; Deng, W.; Zhang, X.; Ung, J.; Nguyen, V.; Zhang, H.; Barrera, M.; Parra, A.; Cowell, J.; et al. TPX-0131, a Potent CNS-penetrant, Next-generation Inhibitor of Wild-type ALK and ALK-resistant Mutations. Mol. Cancer Ther. 2021, 20, 1499 LP - 1507, doi:10.1158/1535-7163.MCT-21-0221.

54. McCusker, M.G.; Russo, A.; Scilla, K.A.; Mehra, R.; Rolfo, C. How I treat ALK-positive non-small cell lung cancer. ESMO open 2019, 4, e000524-e000524, doi:10.1136/esmoopen-2019-000524.

55. Socinski, M.A.; Jotte, R.M.; Cappuzzo, F.; Orlandi, F.; Stroyakovskiy, D.; Nogami, N.; Rodriguez-Abreu, D.; Moro-Sibilot, D.; Thomas, C.A.; Barlesi, F.; et al. Atezolizumab for first-line treatment of metastatic nonsquamous NSCLC. N. Engl. J. Med. 2018, 378, 2288-2301, doi:10.1056/NEJMoa1716948. 
56. Planchard, D.; Popat, S.; Kerr, K.; Novello, S.; Smit, E.F.; Faivre-Finn, C.; Mok, T.S.; Reck, M.; Van Schil, P.E.; Hellmann, M.D.; et al. Metastatic non-small cell lung cancer: ESMO Clinical Practice Guidelines for diagnosis, treatment and follow-up. Ann. Oncol. Off. J. Eur. Soc. Med. Oncol. 2018, 29, iv192-iv237, doi:10.1093/annonc/mdy275. 